\title{
Public sector innovation, e-government, and anticorruption in China and India: Insights from civil servants
}

\author{
Alfred M. Wu ${ }^{1}$ (1) | Yifei $\operatorname{Yan}^{2}$ (1) | Lina $\operatorname{Vyas}^{3}$ ()
}

${ }^{1}$ Lee Kuan Yew School of Public Policy, National University of Singapore, Singapore

${ }^{2}$ Department of Social Policy, London School of Economics, London, UK

${ }^{3}$ Department of Asian and Policy Studies, The Education University of Hong Kong, Hong Kong

\section{Correspondence}

Yifei Yan, Department of Social Policy, London School of Economics, Houghton Street, London WC2A 2AE, United Kingdom.

Email:y.yan10@lse.ac.uk

\begin{abstract}
Both China and India are adopting information and communication technologies to facilitate openness and transparency in their governments, and hence reduce corruption. Distinctive from their traditional anticorruption approaches, is the innovative e-government approach an effective solution to corruption in these two large developing countries? This paper addresses the question through comparative in-depth interviews with 44 mid- or senior-level officials in the public sector in these two countries. The first study of its kind, our research shows that civil servants in both countries overall think positively about transparency and technology in reducing corruption. However, to what extent these innovative measures will be effective is conditional on various factors, such as political willingness, income inequality, and infrastructure readiness. What is worth noting is that the Chinese respondents were more positive regarding the role of transparency, whereas the Indian respondents were more positive about the role of technology, which may reflect the different facilitators of corruption and the constraints of anticorruption in China and India.

\section{KEYWORDS}

anticorruption, China, e-government, India, public sector innovation, qualitative research
\end{abstract}




\section{1 | INTRODUCTION}

Corruption is a global phenomenon that has plagued many countries, including China and India, the two largest emerging economies in the world (Figure 1). Aware of the alarming impact of corruption on economic development and public governance, the governments of both countries have pledged to fight corruption seriously, especially in recent years (Sukhtankar \& Vaishnav, 2015, p. 79; Tang, Ding, \& Xu, 2018). In contrast to the traditional legislative/judicial approaches in India and party-dominated campaigns in China (Vyas \& Wu, 2020), the leveraging of egovernment initiatives to reduce corruption is much more recent and novel. Can this form of public sector innovation curb corruption in China and India?

This paper sheds light on the question posed above from the perspective of civil servants in the two countries. Drawing on open-ended structured interviews with 44 mid- or senior-level officials, in-depth inquiries were made to look into whether or not and if yes, to what extent do they think e-government initiatives work in reducing corruption, the benefits transparency and technology can bring about, and the challenges involved in making these initiatives work.

The present paper contributes to the existing literature in four dimensions. First, through interviewing civil servants, it adds important yet understudied 'insider perspectives' to the extant literature on anticorruption, which mainly taps into the opinions of citizens and experts while ignoring the voices of civil servants who are agents of the state. Second, an in-depth and nuanced understanding of civil servants' perceptions of corruption and anticorruption in China and India contributes to the empirical literature on e-government as a form of public sector innovation for reducing corruption. The role of e-government in anticorruption has so far largely been dominated by quantitative cross-country analyses or ad hoc case studies. Third, we use a nuanced approach to study corruption based on insights from civil servants. Our interview questions seek to understand respondents' views on the impact of economic (growth and inequality), social (education and welfare), and political (ethics and public officials) factors on combating corruption. This allows us to scrutinize the roles of anticorruption drivers and facilitators, as well as the interactions among them, in a richly contextual manner unattainable in cross-country analyses. Furthermore, we do not intend to study e-government in isolation, although the relationship between e-government and corruption reduction has been increasingly investigated recently. As elaborated upon later, the subtle differences in civil servants' perceptions of the role of transparency and technology in reducing corruption in China and India warrant attention. This issue may have profound policy implications. Finally, this paper contributes to the emerging comparative literature on China and India regarding their anticorruption endeavours (Ang, 2014; Murugkar \& Xu, 2012; Vyas \& Wu, 2020). Beyond this specific comparative focus, insights generated here may also be valuable to other developing countries facing similar issues and challenges in relation to corruption.

This paper is organized as follows. The next section presents the background of our study, as well as a summary of the gaps in the existing literature. Section 3 describes the qualitative data and methodology used in this study, followed by a detailed presentation of this study's findings in Section 4. Section 5 discusses the results and presents our conclusions.

\section{2 | BACKGROUND AND LITERATURE GAPS}

Transparency has long been a focus of anticorruption policies. It has also been combined with technology to 'reduce corrupt behaviors by enhancing relationships with citizens and more 
F I G U R E 1 Corruption Perceptions Index, China and India, 1995-2019

Note. A higher score means a cleaner government. From 1995 to 2011, the score ranged between 0 (highly corrupt) and 10 (highly clean); after 2012, the score ranged between 0 (highly corrupt) and 100 (highly clean); to have a consistent figure, the scores between 1995 and 2011 were multiplied by 10 (Data Source: https://www.transparency.org) [Colour figure can be viewed at wileyonlinelibrary.com]

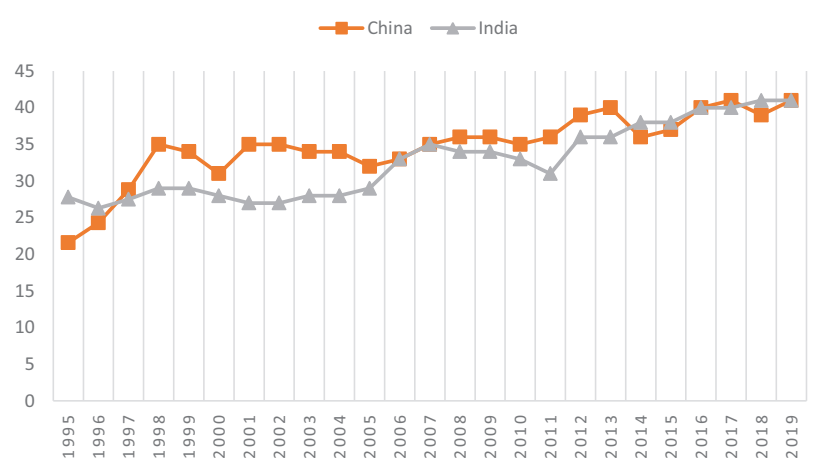

effectively controlling and monitoring [public officials]' (Shim \& Eom, 2008, p. 298). This, however, has only become possible recently, due to technological progress. More specifically, this combination can enhance public governance by 'increasing public access to information, empowering civil society to oversee the state, enabling citizens to track government decisions and actions of public employees, and substantially reducing the costs of transparency efforts' (Nam, 2018, p. 275). As such, e-government, or the use of information and communication technologies to enhance government openness (Hameduddin, Fernandez, \& Demircioglu, 2020) and transparency, is expected to play a substantial role in tackling corruption (Saleem, Wen, \& Khan, 2019). In other words, insofar as public sector innovation is understood as 'the implementation of a product, process, practice, technology, or service that is new to the adopting organization' (Wegrich, 2019, p. 12; see also Osborne \& Brown, 2005), what we see here is the epitome of public sector innovation endeavouring to combat corruption.

Whether or not and to what extent the anticorruption effect of e-government has been realized is a question for empirical investigation. Despite its emergence and steady accumulation, the empirical literature as it stands has gaps in the following two important issues.

The first issue concerns large-scale cross-country studies of corruption; in-depth and small- $N$ studies are called for. The majority of empirical investigations use quantitative approaches to analyse cross-country data. Although the positive anticorruption impact of e-government is observed in these studies (e.g. Anderson, 2009; Choi, 2014; Kim, 2014; Shim \& Eom, 2008), offering encouraging insight, what is presented is largely decontextualized.

Zooming into particular countries' experiences is crucial in gaining an understanding of anticorruption in different contexts and generating relevant policy implications. For example both China and India are documented as increasingly adopting e-government initiatives (Chen \& Aklikokou, 2019; Gupta \& Jana, 2003; Holliday \& Yep, 2005; Kumar \& Best, 2006; Zhou, 2004). However, the link between e-government and corruption reduction has rarely been thoroughly investigated beyond ad hoc case studies (Bhatnagar, 2004, on India) or general discussions (Fan, Zhang, \& Yue, 2009, on China). Therefore, to help researchers and policymakers better anticipate the opportunities and challenges presented in adopting different anticorruption measures, a more in-depth and nuanced understanding is needed. It is necessary to explore whether or not and to what extent e-governments can work. More importantly, an examination of the reasoning behind e-government is urgently needed to supplement the overall picture presented by the previous literature. 
The second issue concerns whose opinions get picked up and at whose cost. With a few exceptions (Graycar, 2014; Jackson \& Smith, 1995; van der Wal, Graycar, \& Kelly, 2016), the primary focus of the literature has been on citizens (CMS, 2018; Li, Gong, \& Xiao, 2016; Su, 2020; Yu, Chen, \& Lin, 2013) and experts' opinions (Song \& Cheng, 2012; Thompson \& Shah, 2005). Most of these extant inquiries have thus fallen short of fully capturing public officials' perceptions. However, these groups are not negligible, as they are the most important 'insiders' regarding anticorruption policies and measures, both as the implementers of such policies as well as their targets. This is particularly the case in many developing countries. Emphasizing the perceptions of 'outsiders' at the cost of 'insiders', the literature on reducing bureaucratic corruption can currently offer only a partial understanding of the nature of corruption, as well as anticorruption measures and approaches (see Gans-Morse et al., 2018; Sukhtankar \& Vaishnav, 2015). In contrast, Li, Lien, Wu, and Zhao (2017) view public officials as important implementers of anticorruption policies. They use the panel data of provincial anticorruption agency heads from 2000 to 2012 to show that both their formal and informal powers help enhance the number of corruption cases brought under investigation. We are not examining objective evidence of the effectiveness of e-government on anticorruption due to the lack of comparative data in China and India. However, a more in-depth understanding of civil servants' perceptions is still deemed both timely and necessary.

\section{3 | DATA AND METHODOLOGY}

We adopted a qualitative approach to effectively address the question of whether or not and if yes, to what extent e-government as a form of public sector innovation, is a solution to corruption in China and India. More specifically, we conducted exploratory interviews using a set of open-ended questions for public officials from one Chinese province and one Indian state. These geographic areas are considered to be average in terms of economic development within their respective countries. The qualitative approach is deemed appropriate as it allows us to conduct an in-depth exploration of both the perceptions of officials as important yet long-neglected 'insiders' and the reasoning behind these perceptions. These elements are rarely investigated in quantitative studies. Similarly, the open-ended questions suit the purpose of our research, as the responses can 'provide detail about perceptions, opinions, personal experiences, and deeply held beliefs' (Julien, 2012, p. 2).

In China, interview questions were distributed to 30 mid-career civil servants during their career training in a renowned local university. They were asked to provide written answers within 1-2 hr in the fall semester of the academic year 2017-2018. During the same period, in India, the interview questions were sent via email to targeted civil servants and politicians through the connections of one of the authors. Although a relatively new qualitative method (Gibson, 2017), email interviews are nevertheless a suitable alternative to face-to-face interviews. They are more convenient to arrange and easy to complete, while still allowing questions and answers to be well thought out (Burns, 2010; James, 2016). These advantages are particularly relevant in our case, as the sensitivity of the topic renders traditional face-to-face interviews difficult to operationalize, particularly in India. Among our 22 potential respondents, two were politicians (one from the ruling party - BJP, and the other from the opposition party) and the remaining were officials from the Indian Administrative Service (IAS) and Provincial Civil Service (PCS). Both politicians, along with the 12 IAS/PCS officials of different ranks in the government, responded. 
Interview questions for Chinese respondents were written in Chinese, whereas the ones distributed to Indian interviewees were in English. The list of questions are comparable across the two versions, which have been validated by experts in anticorruption research. However, the exact sequence and wording of the questions varied slightly, to capture the nuances of the two countries' respective contexts. All interviews were anonymous, in the hope that it would encourage respondents to be more open and frank in sharing their opinions. The survey results indicated that, in both China and India, respondents were quite articulate in regard to the sensitive questions. The complete list of interview questions is available from the authors upon request.

We followed a purposive sampling strategy. We aimed to understand the perceptions of corruption and anticorruption among mid- or senior-level officials. Therefore, certain characteristics of the interviewees, such as familiarity with ethics management and anticorruption, were emphasized. Purposive sampling had therefore been chosen when we implemented the project (Stockemer, 2019).

Our ability to generalize findings from this study might be limited, owing to the small and nonrandom sample. It is, however, worth noting that generalizability to the population is not the main purpose of this qualitative study. The main aim is to gain some first-hand, in-depth insights into the public officials' perceptions regarding e-government, as well as other factors that may reduce the incidence of corruption. This study also aims to compare how and to what extent their opinions are similar or different across the two countries. Hence, this target population allows us to address our research question in a manner that adds fresh insights to the existing literature along the lines identified in the previous section. The limitation in the number of respondents may thus be partly compensated for by the richness of the information provided by these respondents. Similarly, a previous study explored the challenges in adopting e-government initiatives through the interviews of 26 government officials in the United States (Lee \& Kim, 2007).

Questions on the role of transparency, technology, and other factors that may contribute to the reduction of corruption (see Table A1) are situated in the middle part of the question list. The respondents were first asked to evaluate the overall effectiveness of anticorruption initiatives and the quality of anticorruption institutions. These questions are followed by respondents' suggestions of solutions for tackling the issue of corruption. As technology and transparency are the two key elements in e-government initiatives, the questions we asked are as follows:

1. What are your views on transparent government (including e-government)? Please comment on both availability and accessibility.

2. To what extent can the introduction of technology to citizens be effective in combating corruption?

Other anticorruption drivers and facilitators included in the questionnaires were based on an extensive reading of the literature on corruption with specific relevance to the two countries, including two recent syntheses of evidence (Sukhtankar \& Vaishnav, 2015; Tang et al., 2018). In other words, there have been attempts in the literature to link these elements with the levels and prevalence of corruption, and such elements are emerging in the contexts of China and India. In general, they fall into the following categories (which may be interrelated in reality): economic, social, and political factors. In all categories, questions were asked in the following way: 'How do you evaluate the role of ...?'; 'Can ... reduce the level of corruption?'; 'Does ... have a role to play in corruption?'; and so forth (Table A1). Instead of seeking binary 'yes' or 'no' answers, the questions were structured in an open-ended manner that allowed the respondents to write down their thoughts and comments in detail. 
Once collected, the interview data were coded in two stages, using the software NVivo (version 11.0). In the first stage, known as 'open coding', the key concepts and ideas were coded after reading and rereading the interview answers. The option of 'coding in NVivo' was also used when the researchers were unsure about which umbrella certain words or phrases should be put under.

The second stage used 'axial coding', in which different concepts and ideas identified in the first stage were regrouped based on the relationships discerned from this process. Although the literature on research design also recommends a third stage of analysis called 'selective coding' (Babbie, 2012, p. 401), it was deemed unnecessary, as our data had already reached saturation after performing the second stage of coding.

Across all anticorruption drivers and facilitators that were identified, the responses mainly covered three aspects: overall (dis)agreement, further elaborations, and factor-specific additions. In terms of an overall agreement on whether or not some factors were effective in reducing incidences of corruption, there was a fairly clear distinction between those holding the opinion that they were 'useful at least to some extent' versus those who dismissed them as 'of limited or no use'. In some cases, a factor is not necessarily linked to corruption. For some types of anticorruption drivers and facilitators, respondents answered that 'it depends' and even elucidated both the conditions under which they would work and those under which they would not. All answers were therefore categorized under the four labels mentioned above. In further explaining their perceptions, a more nuanced picture emerged in which respondents elaborated on the merits, challenges, and pitfalls of the drivers and facilitators used to make anticorruption strategies effective. Finally, a residual category was created for each anticorruption driver. For instance, when analysing economic factors, 'using a high salary to mitigate corruption (gaoxin yanglian)' was mentioned as a particular policy solution.

The responses from the two countries were analysed separately in the initial stages of the analysis. However, the similar interview structure and the way in which the questionnaires were designed ensured that the responses were largely comparable. The analysis in the next section is based on the same three aspects, which resulted from the coding, as mentioned in the last paragraph.

\section{4 | FINDINGS}

This section reports how the respondents in the public sector in China and India described the way they think about the role of e-government in reducing corruption. Section 4.1 directly compares their views about the effectiveness of transparency and technology, the two essential components of e-government initiatives. More than half of our sample in both countries was positive about the anticorruption potential of e-government through the increase of the cost of corruption or the empowering of the citizenry. However, two interesting nuances within the responses are worth highlighting. First, beyond the overall acknowledgment of the positive anticorruption role of egovernment, the exact weight of this acknowledgment on transparency and modern technology is slightly different between the two groups of respondents in China and India, respectively. This difference is further explored in Section 4.2. Second, the co-existence of general optimism and cautious reservations are observed in other anticorruption drivers and facilitators, which is shown in Section 4.3. Taken together, our findings generate a broad and nuanced picture of anticorruption based on 'insider perceptions', which has rarely been investigated in the literature so far. 


\section{1 | Insider perceptions of e-government in India and China}

A large percentage of the Chinese respondents (22/30) agreed that transparency would be useful in reducing corruption, the potential of which can be fulfilled by 'reducing under-the-table dealings', 'streamlining procedures', and 'increasing the cost of corruption'. Fundamentally, respondents believed that this would enhance the supervisory role of the public. As the minority here, three respondents held the opinion that 'it depends'. They voiced both optimism and concern, and were joined by another five respondents who stated outright that transparency has a limited or no role. Most of these concerns were expressed on the grounds that current government initiatives on transparency may be 'superficial' or 'half-hearted' at best, in which information is 'filtered at multiple levels [before reaching the public]'. Accordingly, 'those having capabilities and [influential and powerful] backgrounds may remain unaffected'. When reflecting on a certain demographic not used to the internet (e.g. the elderly), one respondent voiced that such initiatives might even be harmful.

On the Indian side, $43 \%$ of the respondents (6/14) did not have any comments to make, but more than half of the remaining respondents thought that transparency plays a positive role. The reasons raised, such as 'citizen communication and empowerment' (and, hence, 'public support'), were not substantially different from those expressed by their Chinese counterparts. In addition, they mentioned the 'elimination of middlemen', 'growth and progress', and 'political stability'.

A quarter of the remaining respondents did not think that transparency is useful and were joined by another respondent who argued that 'it depends', given both the merits and challenges of e-government. The concerns they raised were quite different from those on the Chinese side, however. Although Chinese respondents mainly questioned the sincerity of government willingness, Indian respondents were more preoccupied with capacity constraints during the implementation stage, such as the 'lack of infrastructure and officer training', highlighting this issue, 'especially in villages and remote areas'. Without solving these problems simultaneously, if not first, it would take a long time before transparency and e-government initiatives could become effective.

Technology, which is related to the above inquiry into the role of transparency, is the other factor in the agenda of leveraging e-government to fight corruption. Compared with those who thought favourably about transparency, the percentage of Chinese respondents who felt positively about modern technology was slightly lower than that of Indian respondents (17/30). Most comments still centred on enabling citizens and public vigilance. An additional merit mentioned by the respondents was that modern technology also 'offers a convenient channel for reporting wrongdoings'. However, $23.3 \%$ of the Chinese respondents (7/30) thought modern technology was of limited or no use, whereas the answers of another $16.7 \%$ (5/30) were labelled as 'it depends', given both the advantages and shortfalls. One reason for this was that the 'means of corruption are also ever-evolving'; hence, the use of technology could 'drive corruptive behaviour to be more discreet and underground'. Another respondent opined that the current problem may not be to do with clues or reporting, but rather that the actions taken afterward are inadequate. The rise of false, biased, or partial reporting may also have serious implications. It was with these concerns that two of the respondents commented that 'technology is a double-edged sword', whereas another respondent argued that the effectiveness of technology 'depends on the openness of government information as well as the media' and accordingly cautioned that 'anticorruption cannot entirely rely on public vigilance'.

In contrast, 10 out of the 14 Indian respondents did feel that modern technology plays a positive role; half of them linked this to the common rationales they had commented on earlier regarding 
transparency, such as citizen vigilance and the removal of middlemen. The remaining four, who either had reservations or did not agree at all, brought up the argument that 'the introduction of technology to an uneducated population is not effective'. This was similar to the reservation of one Chinese respondent mentioned above regarding the introduction of transparency initiatives to those who are not yet used to the internet.

\section{2 | Different weights on transparency and technology}

It can be seen from the above analysis that the overall level of agreement that transparency and technology would be useful, at least to some extent, was high on both sides. The positive acknowledgment of this innovative method, as well as other anticorruption drivers and facilitators, which will be elaborated upon later, pinpoints that the government (i.e. the administrative branch) has the potential to play a much more active role in both China and India. Traditional anticorruption approaches, such as relying on campaign-style dominated party organs (Fu, 2015; Lang, 2017) or legislative and judicial branches, which tackle some urgent issues, should be reconsidered. Given that these dominant anticorruption approaches lead to mixed results (Zhang \& Kim, 2017; Zhu, Huang, \& Zhang, 2019, on China; Paramahamsa, 2017; Wolf, 2017, on India) and can be politically controversial at times (Li, 2019; Mahmood, 2017), innovative approaches and policy mixes may well be alternatives worth considering to better signal commitment and improve the effectiveness of anticorruption.

However, given the substantially different socioeconomic and political contexts of the two countries, the effectiveness of transparency and technology may manifest itself in a much more nuanced manner. This can also be interrelated with other anticorruption drivers and facilitators, according to the civil servants we interviewed.

From the perspective of our Chinese respondents, transparency is more critical for anticorruption than technology, though they cautioned that transparency needs to be analysed in greater depth for it to work toward reducing corruption. Indian respondents were more enthusiastic regarding technology than transparency initiatives. It is possible that existing and more traditional forms of engagement with transparency (other than e-government) are already higher in the Indian context, with its renowned right-to-information campaign resulting in the 2005 Right to Information (RTI) Act. In contrast, traditional transparency initiatives in China are much less proactive. For instance, one of the most prominent manifestations of transparency, the Regulations of the People's Republic of China on Open Government Information, adopted in 2008 and revised in 2019 , is only a government regulation, rather than a law. The limited effectiveness of transparency with regard to reining in corruption is also reflected in the reservations of some Chinese respondents, whose concerns over its effectiveness were mainly about whether or not the government is sincerely committed to being transparent. Indian officials, on the other hand, pointed out that better education and improved infrastructure are crucial for technology to work in combating corruption.

\subsection{What corruption is (not): A broader picture}

Different perceptions of the roles and limitations of transparency versus technology further shed light on the nuanced understanding of the nature of corruption held by Chinese and Indian civil servants. The respondents did not consider this problem to be purely economic. Only half of our 
Chinese respondents (15/30) agreed that economic development would help bring down corruption, as it could 'reduce demand for corruption', 'raise levels of civility', and 'benefit the citizenry'. More than a quarter of the respondents (8/30) questioned the effectiveness of this association. Some argued that corruption is more a social or psychological phenomenon (rather than economic) by contrasting the current period with the Mao era, which they believed to have a lower prevalence of corruption, despite greater overall poverty. Some argued that the reason for corruption is instead more institutional (i.e. the inadequacy of supervision). Some even believed that economic growth would elicit more corruption or would not mitigate it, at least in the initial phases of growth. The remaining respondents (7/30) argued that corruption and economic growth are not necessarily related.

On the Indian side, the number of respondents who recognized the corruption-reducing role of economic development was equal to the number of those who disagreed (6/14). For the former, besides similar arguments to those raised by their Chinese counterparts (e.g. that economic development would reduce the demand for corruption), other mechanisms cited included 'blocking the means of keeping and spending black money' and 'promoting market competition through decentralization'. Those who disagreed presented a more institutional perspective, in which 'only proper implementation and strict punishment will solve the problem'. Other respondents argued that 'rich people may demand more from poor people', or that the 'level of economic development [that can reduce corruption]' has not yet been reached.

Compared with e-government and other factors that may reduce corruption, the number of respondents who believed simply increasing the level of economic development would reduce corruption was the lowest in both countries. This is quite different from the typical Western view of corruption as mainly an economic issue (and, hence, deregulation and market-oriented reform as the typical ameliorative policy suggestions; Bertot, Jaeger, \& Grimes, 2010, p. 265).

Beyond this agreement, there were substantial differences regarding the nature of corruption. For the Chinese respondents, it was more about the distribution of development benefits in terms of income and social welfare. For the Indian respondents, it was more about the development level and accessibility of social services to the disadvantaged. This also largely echoes the development status of the two countries. According to World Bank statistics, India's poverty headcount ratio has been higher than that of China since the 2000s. In contrast, China's income gap between the rich and the poor is more alarming.

For Chinese respondents, income disparity was one of the cruxes of corruption; a vast majority of respondents (27/30) acknowledged that it plays a role. This is also in line with income disparity and corruption being ranked as the top concerns of ordinary Chinese citizens (Gong \& Wu, 2012; Han \& Whyte, 2009). Although (increased levels of) economic development reduce the demand for corruption, several respondents mentioned that inequality would raise this demand by making poor officials feel unfairly treated. One respondent even referred to the concept of class stratification, as civil servants are not compensated sufficiently. Although the percentage of Indian respondents who felt the same was lower (8/14), the mechanisms cited for the link between disparity and corruption were similarly along the lines of increased demand for corruption. As one respondent put it, disparity means that 'people try to compete with others'; 'to win this horse race, they go to any extent of corruption to fulfil their needs'.

Only two of the Chinese respondents thought that income disparity is not necessarily relevant to corruption. One felt that a certain amount of disparity is reasonable; 'otherwise, there would be no motivation for socioeconomic development' (he did, however, recognize the importance of 'preventing [individuals from] becoming rich through corruptive means'). Another respondent rejected the possibility of 'venturing into corruption just to keep up with the salary scales of 
colleagues in urban areas or more senior officials' himself, whereas a third of the respondents talked about 'using high salaries to mitigate corruption/cultivate frugality' as a solution (see Wu, 2014a, 2014b, on civil service salary and anticorruption in China), without directly commenting on inequality.

In contrast, the percentage of such thinking on the Indian side was higher (6/14). Some held a pessimistic view that 'all, irrespective of salary, demand bribes'. Another respondent first gave an ambiguous answer of 'could be' (i.e. income disparity could have a role to play in breeding corruption), but then argued that such issues could not be corrected, as 'the manager and the clerk cannot be paid similarly (which means that egalitarianism also harms civil service management)'. Still, others pointed to poor ethical standards as the core issue (this point will be elaborated upon later). Additional negative comments included the idea that disparity 'will lead to crime, not corruption', which sheds light on the complexities of the impact of income inequality.

In a similar vein, $90 \%$ of our Chinese respondents generally agreed that social welfare programs are useful in reducing corruption. In addition to explicitly mentioning the reduction of inequality, they brought up other mechanisms through which welfare programs may work, including the 'increase of satisfaction and feelings of happiness' and 'constraints on the opportunities for and benefits of corruptive behaviours'. One respondent added a further qualification that the monitoring of such programs is nevertheless needed in practice. The very few remaining respondents conceded that welfare programs 'may not be the most fundamental solution', though they may 'reduce the sympathy felt by the public toward corrupt officials'.

Only two of the Indian respondents expressed outright disagreement with the positive role of welfare programs in combating corruption. They worried that 'people still will bribe to get things done'. There were even respondents who saw 'welfare programs [as] a source of corruption'. Two more respondents gave an ambivalent opinion of 'could/maybe', whereas another four respondents mentioned key anticorruption drivers other than welfare programs, including education (awareness and literacy) programs, firm leadership by the government (with more severe punishments for offenders based on the severity of the case), and e-government (digitalization). For the remaining respondents (6/14) who acknowledged the positive role of welfare programs, most illustrated their points with concrete examples from education, welfare subsidies, and various other central and state government schemes, without elaborating on why they thought the programs were successful. One respondent nonetheless cautioned that welfare and other income redistributive programs must be practical and accessible to be effective.

The perception of educational attainment is the second dimension of social development that we examined. A slightly lower percentage of Chinese respondents (21/30) believed educational attainment played a positive role in corruption reduction, in contrast to their perceptions on income inequality, although the rationales mentioned were quite diverse. They included 'civic attitude', 'democratic awareness/awareness of rights', and the 'raising of citizens' calibre', just to name a few. Some respondents believed that better educated citizens might play a better monitoring role. On the Indian side, nearly $70 \%$ of respondents (9/14) thought similarly. Reasons they cited include 'awareness of right and wrong, 'citizens' rights and responsibilities', and 'ethical values or behaviour', are not so different from those of their Chinese counterparts. Likewise, a similar percentage of respondents (around 30\%) in these two countries did not think that education necessarily has a role to play in combating corruption. Some argued that 'being educated' does not mean 'having a high [moral] calibre'. As will be seen in the next paragraph, these two concepts were often conflated, especially in the Chinese context. Others commented that corruption also has to do with the broader social environment. 
Finally, regarding the political dimension, our results suggest that the low ethics of officials are the most important root cause of corruption, according to Indian respondents. The Chinese view was more mixed. Regarding perceptions of the ethical standards of politicians/officials, among our Chinese respondents, 40\% (12/30) gave an ambiguous answer ('it depends'); being an official in China does not necessarily indicate a high ethical standard. In other words, the two are not necessarily related. The rest of the respondents, who gave clear-cut opinions, were equally divided between seeing officials as having higher ethical standards and believing otherwise. Even amongst the former, the reasons raised were sometimes not that closely and strictly linked to ethics. By saying that officials 'are social elites', 'have experienced higher education', and 'are [in their positions] after several rounds of selection', they were indeed referring to officials' education levels, social status, and job prestige, rather than their ethical standards. Some of these points were refuted by those who did not perceive officials as having a higher moral calibre. For example, several respondents mentioned that 'morality is not necessarily linked to the rankings of officials'; it may not have any connection at all with whether or not a person is an official. Moreover, respondents with the latter opinion cautioned that, when 'cadre selection criteria are not transparent and based on seniority [rather than performance]', they may even create many officials with low ethical standards. There were also more cynical views that 'only very few officials have integrity and high moral standards. However, such officials are not favoured by either their seniors or juniors'.

Unlike the Chinese respondents, who expressed diverse opinions on ethical standards, Indian respondents almost universally ranked the ethical standards of politicians/officials in the 'low' category. Indeed, their sentiments were either cynical ("politicians try to project a very moral image of themselves in public, but when it comes to actual life, it is the reverse') or strong ('this field requires a focused anticorruption drive'), if not both. Perhaps the only silver lining in the unequivocal laments was the brief statement that 'things are changing for the better', made by the same respondent who accused politicians and officials with low ethical standards of being the main source of corruption.

Another political dimension explored was whether or not the appointment of important positions would cause chain reactions of corruption (i.e. officials getting involved in corruption because their senior officials are corrupt). Eighty percent of the Chinese respondents answered 'yes' to this question, with the mention of positive effects on corruption (i.e. appointing 'clean' officials makes the government less corrupt) slightly more frequent than that of negative effects. The remaining few respondents were less positive in their answers. In particular, some respondents did not believe that any chain reactions exist. Instead, they argued that corruption is 'too institutional for any individual to intervene forcefully' or that 'it is less about the position than the person'. That is in fighting corruption, institutional anticorruption arrangements are much more instrumental than attempts to prevent individual corrupt officials from catalysing more corruption.

A slightly higher percentage of Indian respondents (12/14) agreed that there is a chain effect, although very few elaborated further on this opinion. A positive effect was mentioned only once: 'If appointments to important positions are properly made, then we will have honest people who will combat corruption'. Some negative comments counterbalanced this. For instance, some respondents stated that corrupt officials may 'help their own people take undue advantage most of the time'. Similarly, 'if corrupt officials are in important positions, then it will increase corruption'. One respondent made a further call that 'all appointments should be [made] on merit'. Only two of the Indian respondents stated otherwise. 


\section{5 | DISCUSSION AND CONCLUSION}

Public sector innovation is broadly considered as necessary to solve economic and social problems (see Demircioglu, 2019, p. 1). As rampant corruption remains a severe problem in many parts of the developing world, the anticorruption potential of e-government innovation has increasingly interested scholars, practitioners, and policymakers alike. Unlike earlier studies, which either present a cross-country picture or single case studies, this paper is the first of its kind to examine the potential and limitations of using e-government as an innovative anticorruption measure from the perspective of public officials in two of the world's largest developing countries. This question is further explored alongside their perceptions on other anticorruption endeavours, which not only yields important insights into the nature of corruption in these two countries, but also sheds light on important policy measures with regard to how corruption can be better tackled.

In addition to enriching the extant literature through an in-depth exploration of government officials' 'insider perspectives', the findings also yield practical implications for anticorruption policymaking in the two countries, as well as other developing countries facing similar challenges. As can be observed from our analysis, respondents still had concerns and reservations, even with regard to facilitators that received the most endorsement for their usefulness in reducing corruption (e.g. reducing income inequality in the Chinese context or strengthening moral education for public officials in the Indian context). In other words, none of the anticorruption drivers and facilitators would suffice if used alone. The introduction of e-government is no exception. Our findings echo evidence from cross-country studies, in that the extent to which e-government will be an effective anticorruption measure (or improve public governance) varies based on the political, economic, and cultural conditions of a country (Ho \& Im, 2015; Nam, 2018; van der Wal \& Demircioglu, 2020; Zhang, 2015).

The limitations of individual policy measures are by no means a problem exclusive to fighting corruption. Indeed, nearly all institutional arrangements would face a distinctive set of imperfections if used individually (Wu \& Ramesh, 2014). Therefore, the task underlying anticorruption governance is to devise a policy mix that can synergize the merits of different instruments while minimizing, if not cancelling out, their limitations.

Just as corruption is perceived as a complex socioeconomic problem (rather than as a purely economic phenomenon), the policy mix should be comprehensive and much broader than merely focusing on vigilance, monitoring, and punishment aspects wherein the above measures primarily view public officials as policy targets. The motivations of public officials are complex. As mentioned by Leong and Howlett (2017), besides avoiding blame, they aim to claim credit and retain their legitimacy and credibility, which the adoption of egovernment innovation possibly tackles. In terms of innovative modern technologies, their adoption may require that the accessibility and quality of education be improved simultaneously to enhance the usage of such technologies. These complementarities were brought up by the respondents in various parts of the interviews. Given that, in our interviews, individual categories of factors were scrutinized one by one, without overarching questions linking them together, the interaction effects of different drivers and facilitators are beyond the scope of this paper. Nevertheless, it remains a topic worth further exploration, in order to identify one or more viable policy mix(es) that could be used to combat corruption.

In summary, adopting information and communication technologies to facilitate openness and transparency in government is already a nascent and emerging innovation in the fight against corruption in China and India. Although cross-country studies suggest that this should be a promising method for reducing corruption, insider perspectives in the Chinese and Indian 
contexts indicate that a more nuanced approach to fighting corruption and improving openness and transparency in government is needed.

Through a qualitative analysis of in-depth interviews with 44 officials, this paper investigated in detail these perceptions held by public officials in the two countries, a critical aspect that few studies in the literature have scrutinized. Our results suggest that, although respondents in both countries believe that various measures - be they e-government or economic and political ones can be useful in tackling corruption, none of them would be sufficient when used as a standalone measure. Therefore, they would need to be supplemented with other measures.

The perceived limitations of each of these measures in turn reflect how civil servants in the two countries interpret the nature of corruption. The majority of the Chinese civil servants and their Indian counterparts viewed corruption as more than an economic issue, which differs substantially from the dominant view in Western countries, which is also held by international organizations (Bertot et al., 2010, p. 265). However, for China, the priority in reducing corruption is strengthening political commitment to e-government initiatives and, more broadly, reducing income inequality in society. In contrast, the obstacle to e-government effectively reining in corruption in India manifests more in the form of a lack of essential services, such as infrastructure and education in remote rural areas. Such complementarities and interrelations of different anticorruption drivers and facilitators deserve to be contextualized and clarified more systematically, to facilitate more well-rounded policy design and implementation. This will allow the full realization of such policies' potential. For instance, future research may further differentiate different types of corruption (Graycar, 2015) and investigate what kind or stage of e-government arrangements (Moon, 2002) is most effective in combating these various forms of corruption. This paper thus serves as a valuable starting point on which these inquiries can build.

\section{ACKNOWLEDGMENTS}

The authors are indebted to Adam Graycar, M. Shamsul Haque, M. Jae Moon, Olga Sazhina, Xu Wei, and Yifan Hu for their helpful inputs on earlier versions of this paper. A note of special thanks goes to Zeger Van der Wal and Mehmet Akif Demircioglu. The authors also benefited from helpful comments from the editors and the anonymous referees.

\section{O R C I D}

Alfred M. Wu (iD https://orcid.org/0000-0002-2689-6285

Yifei Yan (D) https://orcid.org/0000-0003-2833-5972

Lina Vyas (1) https://orcid.org/0000-0003-4377-2572

\section{REFERENCES}

Andersen, T. B. (2009). E-government as an anticorruption strategy. Information Economics and Policy, 21(3), 201210.

Ang, Y. Y. (2014). Authoritarian restraints on online activism revisited: Why "I-paid-a-bribe” worked in India but failed in China. Comparative Politics, 47(1), 21-40.

Babbie, E. (2012). The practice of social research (12th ed.). Belmont, MA: Wadsworth Cengage Learning.

Bertot, J. C., Jaeger, P. T., \& Grimes, J. M. (2010). Using ICTs to create a culture of transparency: E-government and social media as openness and anticorruption tools for societies. Government Information Quarterly, 27(3), 264-271.

Bhatnagar, S. (2004). E-government: From vision to implementation: A practical guide with case studies. New Delhi, India: Sage Publications.

Burns, E. (2010). Developing email interview practices in qualitative research. Sociological Research Online, 15(4), $24-35$. 
Chen, L., \& Aklikokou, A. K. (2019). Relating E-government development to government effectiveness and control of corruption: A cluster analysis. Journal of Chinese Governance. https://doi.org/10.1080/23812346.2019.1698693

Choi, J. W. (2014). E-government and corruption: A cross-country survey. World Political Science, 10(2), $217-236$.

CMS. (2018). CMS-India corruption study 2018: 2005 to 2018: How well are states placed? Retrieved from http:// cmsindia.org/cms_ics18/CMS_ICS_2018_Report.pdf

Demircioglu, M. A. (2019). The effects of organizational and demographic context for innovation implementation in public organizations. Public Management Review. https://doi.org/10.1080/14719037.2019.1668467

Fan, Y., Zhang, Z., \& Yue, Q. (2009). E-government, transparency and anti-corruption. International Conference on Management of e-Commerce and e-Government, 2009, 101-104.

Fu, H. (2015). Wielding the sword: President Xi's new anticorruption campaign. In S. Rose-Ackerman \& P. F. Lagunes (Eds.), Greed, corruption, and the modern state: Essays in political economy (pp. 134-157). Cheltenham, UK: Edward Elgar Publishing.

Gans-Morse, J., Borges, M., Makarin, A., Mannah-Blankson, T., Nickow, A., \& Zhang, D. (2018). Reducing bureaucratic corruption: Interdisciplinary perspectives on what works. World Development, 105, 171-188.

Gibson, L. (2017). Type me your answer. In D. Gray, V. Clarke, \& V. Braun (Eds.), Collecting qualitative data: A practical guide to textual, media and virtual techniques (pp. 211-212). Cambridge, UK: Cambridge University Press.

Gong, T., \& Wu, A. M. (2012). Does increased civil service pay deter corruption? Evidence from China. Review of Public Personnel Administration, 32(2), 192-204.

Graycar, A. (2014). Awareness of corruption in the community and public service: A Victorian study. Australian Journal of Public Administration, 73(2), 271-281.

Graycar, A. (2015). Corruption: Classification and analysis. Policy and Society, 34(2), 87-96.

Gupta, M. P., \& Jana, D. (2003). E-government evaluation: A framework and case study. Government Information Quarterly, 20(4), 365-387.

Hameduddin, T., Fernandez, S., \& Demircioglu, M. A. (2020). Conditions for open innovation in public organizations: Evidence from challenge.gov. Asia Pacific Journal of Public Administration, 42(2), 111-131.

Han, C., \& Whyte, M. K. (2009). The social contours of distributive injustice feelings in contemporary China. In D. S. Davis \& F. Wang (Eds.), Creating wealth and poverty in postsocialist China (pp. 193-212). Stanford, CA: Stanford University Press.

Ho, A. T., \& Im, T. (2015). Challenges in building effective and competitive government in developing countries: An institutional logics perspective. The American Review of Public Administration, 45(3), 263-280.

Holliday, I., \& Yep, R. (2005). E-government in China. Public Administration and Development, 25(3), $239-249$.

Jackson, M., \& Smith, R. (1995). Everyone's Doing it! Codes of ethics and New South Wales parliamentarians' perceptions of corruption. Australian Journal of Public Administration, 54(4), 483-493.

James, N. (2016). Using email interviews in qualitative educational research: Creating space to think and time to talk. International Journal of Qualitative Studies in Education, 29(2), 150-163.

Julien, H. (2012). The SAGE encyclopedia of qualitative research methods. Thousand Oaks, CA: SAGE Publications.

Kim, C. K. (2014). Anticorruption initiatives and e-government: A cross-national study. Public Organization Review, 14(3), 385-396.

Kumar, R., \& Best, M. L. (2006). Impact and sustainability of e-government services in developing countries: Lessons learned from Tamil Nadu, India. The Information Society, 22(1), 1-12.

Lang, B. (2017). China's anti-graft campaign and international anticorruption norms: Towards a "new international anticorruption order"? Crime, Law and Social Change, 70(3), 331-347.

Lee, J., \& Kim, J. (2007). Grounded theory analysis of e-government initiatives: Exploring perceptions of government authorities. Government Information Quarterly, 24(1), 135-147.

Leong, C., \& Howlett, M. (2017). On credit and blame: Disentangling the motivations of public policy decisionmaking behavior. Policy Sciences, 50, 599-618.

Li, H., Gong, T., \& Xiao, H. (2016). The perception of anticorruption efficacy in China: An empirical analysis. Social Indicators Research, 125(3), 885-903.

Li, L. (2019). Politics of anticorruption in China: Paradigm change of the Party's disciplinary regime 2012-2017. Journal of Contemporary China, 28, 47-63.

Li, L., Lien, D., Wu, Y., \& Zhao, Y. (2017). Enforcement and political power in anticorruption-Evidence from China. World Development, 98, 133-147. 
Mahmood, Z. (2017). Politics sans economics: Commentary on the political economy of demonetization in India. Journal of the Global South, 8, 71-85.

Moon, M. J. (2002). The evolution of e-government among municipalities: Rhetoric or reality? Public Administration Review, 62(4), 424-433.

Murugkar, M., \& Xu, Z. (2012). Stepping towards transparency: India's Right to Information Act and China's Open Government Information Regulation. India China Institute Working Paper. Retrieved from http://indiachinainstitute.org/wp-content/uploads/2012/04/SteppingTowardsTransparency-REVIEWERREADY.pdf

Nam, T. (2018). Examining the anticorruption effect of e-government and the moderating effect of national culture: A cross-country study. Government Information Quarterly, 35(2), 273-282.

Osborne, S. P., \& Brown, K. (2005). Managing change and innovation in public service organizations. London, UK: Routledge.

Paramahamsa, R. (2017). Demonetisation: To deify or demonize? Economic Survey, 2016-2017, 53-81.

Saleem, H., Wen, J., \& Khan, M. B. (2019). Determinants of corruption in China: A policy perspective. Journal of Chinese Governance. https://doi.org/10.1080/23812346.2018.1516388

Shim, D. C., \& Eom, T. H. (2008). E-government and anticorruption: Empirical analysis of international data. International Journal of Public Administration, 31(3), 298-316.

Song, X., \& Cheng, W. (2012). Perception of corruption in 36 major Chinese cities: Based on survey of 1,642 experts. Social Indicators Research, 109(2), 211-221.

Stockemer, D. (2019). Quantitative methods for the social sciences: A practical introduction with examples in SPSS and Stata. Cham, Switzerland: Springer.

$\mathrm{Su}, \mathrm{S}$. (2020). Why so few acting whistleblowers? Impacts of institutional anticorruption. Governance, 33(2), 227247.

Sukhtankar, S., \& Vaishnav, M. (2015). Corruption in India: Bridging research evidence and policy options. In S. Shah, A. Panagariya, \& S. Gokarn (Eds.), India Policy Forum (Vol. 11, pp. 193-276). Delhi, India: National Council of Applied Economic Research.

Tang, N., Ding, Z., \& Xu, Y. (2018). Corruption and anti-corruption research in China: A critical review of Chinese top journal publications (1989-2017). Chinese Public Administration Review, 9(2), 79-98.

Thompson, T., \& Shah, A. (2005). Transparency international's corruption perceptions index: Whose perceptions are they anyway? Retrieved from http://siteresources.worldbank.org/PSGLP/Resources/ ShahThompsonTransparencyinternationalCPI.pdf

van der Wal, Z., Graycar, A., \& Kelly, K. (2016). See no evil, hear no evil? Assessing corruption risk perceptions and strategies of Victorian public bodies. Australian Journal of Public Administration, 75(1), 3-17.

van der Wal, Z., \& Demircioglu, M. A. (2020). Public sector innovation in the Asia-pacific trends, challenges, and opportunities. Australian Journal of Public Administration. https://doi.org/10.1111/1467-8500.12435

Vyas, L., \& Wu, A. M. (2020). Anti-corruption policy: China's Tiger Hunt and India's demonetization. International Journal of Public Administration, 43(11), 1000-1011.

Wegrich, K. (2019). The blind spots of collaborative innovation. Public Management Review, 21(1), 12-20.

Wolf, M. (2017). India's bold experiment with cash. Financial Times. Retrieved from https://www.ft.com/content/ e3f2aaa8-f77d-11e6-bd4e-68d53499ed71

Wu, A. M. (2014a). Governing civil service pay in China. Copenhagen, Denmark: NIAS Press.

Wu, A. M. (2014b). Searching for fiscal responsibility: A critical review of the budget reform in China. China: An International Journal, 12(1), 87-107.

Wu, X., \& Ramesh, M. (2014). Market imperfections, government imperfections, and policy mixes: Policy innovations in Singapore. Policy Sciences, 47(3), 305-320.

Yu, C., Chen, C. M., \& Lin, M. W. (2013). Corruption perception in Taiwan: Reflections upon a bottom-up citizen perspective. Journal of Contemporary China, 22(79), 56-76.

Zhang, Y., \& Kim, M. H. (2017). Do public corruption convictions influence citizens' trust in government? The answer might not be a simple yes or no. The American Review of Public Administration, 48(7), 685-698.

Zhang, Z. (2015). Crowding out meritocracy?-Cultural constraints in Chinese public human resource management. Australian Journal of Public Administration, 74(3), 270-282.

Zhou, X. (2004). E-government in China: A content analysis of national and provincial web sites. Journal of Computer-Mediated Communication, 9(4), JCMC948. 
Zhu, J., Huang, H., \& Zhang, D. (2019). “Big Tigers, Big Data”: Learning social reactions to China’s anticorruption campaign through online feedback. Public Administration Review, 79(4), 500-513.

How to cite this article: Wu AM, Yan Y, Vyas L. Public sector innovation, e-government, and anticorruption in China and India: Insights from civil servants. Aust J Publ Admin. 2020;1-16. https://doi.org/10.1111/1467-8500.12439

\section{APPENDIX}

TA B LE A 1 Interview questions for different anticorruption drivers and facilitators

\begin{tabular}{|c|c|c|}
\hline Categories & $\begin{array}{l}\text { Anticorruption } \\
\text { drivers and } \\
\text { facilitators }\end{array}$ & Interview questions \\
\hline \multirow[t]{2}{*}{ E-government } & Transparency & $\begin{array}{l}\text { What are your views on transparent government (including } \\
\text { e-government)? Please comment on both availability and accessibility. }\end{array}$ \\
\hline & Technology & $\begin{array}{l}\text { To what extent can the introduction of technology to citizens be } \\
\text { effective in combating corruption? }\end{array}$ \\
\hline \multirow[t]{2}{*}{ Economic } & Economic growth & $\begin{array}{l}\text { Can a higher level of economic development reduce the level of } \\
\text { corruption? }\end{array}$ \\
\hline & $\begin{array}{l}\text { Income } \\
\text { inequality }\end{array}$ & $\begin{array}{l}\text { Does income disparity have a role to play in corruption? How can we } \\
\text { handle this situation? }\end{array}$ \\
\hline \multirow[t]{2}{*}{ Social } & Education & $\begin{array}{l}\text { Does the improvement of the educational attainment of citizens act as a } \\
\text { tool to combat corruption? }\end{array}$ \\
\hline & Welfare programs & $\begin{array}{l}\text { Can there be any social welfare programs (including but not limited to } \\
\text { health care, social assistance to the poor, and retirement protection) } \\
\text { that can help combat corruption? }\end{array}$ \\
\hline \multirow[t]{2}{*}{ Political } & Politician ethics & Do you think that politicians have high ethical standards? \\
\hline & $\begin{array}{l}\text { Appointment of } \\
\text { important } \\
\text { positions }\end{array}$ & $\begin{array}{l}\text { Do appointments to important positions lead to the chain reactions of } \\
\text { corrupt practices? }\end{array}$ \\
\hline
\end{tabular}

